\title{
La prueba rápida MODS: Una necesidad creciente de descentralización en nuestro país
}

\author{
The quick test MODS: A growing need of decentralization in our country
}

\section{Sr. Editor:}

La tuberculosis (TB) es una de las enfermedades infecciosas con mayor tasa de incidencia y mortalidad a nivel mundial. Perú ocupa el segundo lugar en las Américas, con aproximadamente 31000 casos el 2011, y 2190 casos de TB multidrogo resistente (TBMDR) (1).

La Red Nacional de Laboratorios en Salud Pública del Perú, viene utilizando métodos rápidos para la detección de TB y TB-MDR: La prueba de nitrato reductasa (Griess), método de susceptibilidad a drogas por observación microscópica (MODS), el método genotípico Genotype MTBDR plus®, entre otras (2). MODS fue creada y estandarizada en nuestro país, consiste básicamente en observar por un microscopio invertido el crecimiento de microcolonias con un patrón específico de Mycobacterium tuberculosis, por tanto es útil para el diagnóstico y para determinar resistencia a isoniacida (INH) y rifampicina (RMP) (3).

Desde la creación de MODS, se han publicado en el mundo estudios acerca de su desempeño y aplicabilidad; en el meta-análisis de Minion y col (4) de nueve estudios sobre la eficacia de MODS, en el diagnóstico de resistencia a RMP, se estimó una sensibilidad agrupada de 98,0\% (95\% CI 94,5-99,3) y una especificidad agrupada de 99,4\% (95,7-99,9), y con la INH fue $97,7 \%(94,4-99,1)$ de sensibilidad y $95,8 \%(88,1-98,6)$ en especificidad, asimismo estimó el tiempo promedio de respuesta en 9,9 días (95\% CI $4,1-15,8)$. De esta manera queda demostrada la alta rentabilidad diagnóstica frente el resto de pruebas convencionales, siendo una prueba altamente costoefectiva sobretodo en relación al método Genotype MTBDR plus ${ }^{\circledR}$, el cual es aproximadamente 11 veces más costosa (2).

Actualmente, se observa su creciente utilización a nivel mundial, debido a que es una técnica innovadora y llamativamente no tiene patente, por lo que su reproducción es libre, además cuenta con el respaldo de la Organización Mundial de Salud, que ha designado a MODS el estándar de oro para el diagnóstico rápido de TB/TB MDR (5). Algunos países del hemisferio ya la tienen dentro de sus guías clínicas y otros van generando la evidencia necesaria para ello, así como se demuestra en el estudio de Shah y col (6) en el que concluyen que en pacientes con sospecha de TB y co-infección de VIH, MODS tuvo una elevada sensibilidad y especificidad para el diagnóstico rápido de TB y TB-MDR, por tanto recomiendan que MODS debe ser usada en similares regiones con bajos recursos y alta carga de co-infección de TB y VIH.

A pesar que nuestro país tiene una mayor carga de TB/TB-MDR, la prueba ha sido parcialmente descentralizada en algunas direcciones de Salud (DISA); desafortunadamente sólo cuatro laboratorios lo procesan, entre ellos, Callao, Lima Sur, Arequipa e Ica, generando mayor carga de trabajo y lentitud en el proceso diagnóstico del resto del país. El tiempo promedio de esta descentralización se evidencia en el estudio de Mendoza-Ticona y col (7), siendo de 94, 97 y 173 días, para las DISA de Callao, Lima Sur y Arequipa respectivamente, con una sensibilidad y especificidad para la detección de TB-MDR mayor a $95 \%$.

De lo referido se infiere, que tanto la duración de la descentralización como el costo de la prueba por paciente, no constituyen una barrera para que ésta se implemente en el resto de provincias de nuestro país, donde existe una elevada tasa morbi-mortalidad por TB/TB-MDR. En el ámbito de la Salud Pública, para decidir la implementación de una determinada prueba, se toman en cuenta determinados factores, aparte de los dos ya referidos, se puede mencionar a los requerimientos de facilidades de laboratorio y el nivel de entrenamiento de personal necesario, así como la prevalencia en la zona (8). 
Es evidente la necesidad de descentralización de MODS a la mayoría de las regiones de nuestro país, tanto por su bajo costo y alta efectividad, como por la doble función que cumple, la de diagnóstico e identificación de resistencia, generando mayor cantidad de beneficiarios. La descentralización sería principalmente un trabajo multisectorial, tanto del Instituto Nacional de Salud, universidades e inclusive instituciones privadas.

Juan J. Pareja-Ramos

Estudiante de Medicina. Sociedad Científica de Estudiantes de Medicina de la Universidad Privada Antenor Orrego (SOCIEM-UPAO). Escuela de Medicina, Universidad Privada Antenor Orrego. Trujillo, Perú.

Patricia C. Huamán-Orosco

Estudiante de Medicina. Sociedad Científica de Estudiantes de Medicina, Universidad Nacional San Luis Gonzaga (SOCEMI). Facultad de Medicina Humana, Universidad Nacional San Luis Gonzaga. Ica, Perú.

Julio Torres-Chang Médico Neumólogo. Hospital Regional Docente de Ica, Ministerio de Salud. Lima, Perú. Facultad de Medicina Humana, Universidad Nacional San Luis Gonzaga. Ica, Perú.

\section{REFERENCIAS BIBLIOGRÁFICAS:}

1. Organización Panamericana de la Salud. La Tuberculosis en la Región de las Américas. Informe Regional 2011. Epidemiología, control y financiamiento (Internet). Washington, DC: OPS/ OMS;2011 (citadoel 10defebrerode2013). Disponible en: http://new.paho.org/hq/index.php?option $=\mathrm{com}_{-}$ docman\&task $=$ doc_view\&gid $=19511 \&$ Itemid $=$

2. Solari L, Gutiérrez-Aguado A, Suárez C. Análisis de costos de los métodos rápidos para diagnóstico de tuberculosis multidrogorresistente en diferentes grupos epidemiológicos del Perú. Rev Peru Med Exp Salud Pública. 2011; 28(3):426-31.

3. Moore DA, Evans CA, Gilman RH, et al. Microscopicobservation drug-susceptibility assay for the diagnosis of TB. N Engl J Med. 2006; 355(15):1539-50.

4. Minion J, Leung E, Menzies D, Pai M. Microscopicobservation drug susceptibility and thin layer agar assays for the detection of drug resistant tuberculosis: a systematic review and meta-analysis.Lancet Infect Dis. 2010; 10:688-698.

5. World Health Organization. Noncommercial culture and drug-susceptibility testing methods for screening patients at risk for multidrug-resistant tuberculosis: policy statement (Internet). Ginebra: WHO; 2011. (Citado el 13 de Marzo del2013). Disponible en: http:// whqlibdoc.who.int/publications/2011/ 9789241501620_eng.pdf

6. Shah NS, Moodley P, Babaria P. Rapid diagnosis of tuberculosis and multidrug resistance by the microscopic- observation drug- susceptibility assay. Am J Respir Crit Care Med. 2011; 183(10):1427-33.

7. Mendoza A, Castillo E, Gamarra N, et al. Reliability of MODS assay decentralization process in three regions in Peru. Int J Tuberc Lung Dis. 2011; 2:21722.

8. Van Deun A, Martin A, Palomino JC. Diagnosis of drug-resistanttuberculosis: reliability and rapidity of detection. Int J Tuberc Lung Dis. 2010; 14(2):131-40.

Recibido: 20/04/2013

Aceptado: 14/05/2013

\section{Comentario de los editores}

\section{Comments from Editors}

Desde el descubrimiento del MODS en el año 2000 (1), diversos estudios han demostrado las bondades diagnósticas del método para detección de TB y diagnóstico de resistencia incluso en poblaciones de pacientes con co-infección TB VIH (2). Existen algunos reportes contradictorios sobre diferente sensibilidad o alto nivel de contaminación del método, pero estos siguen siendo similares a otros cultivos líquidos. Los hallazgos y dudas mencionados anteriormente se aclaran con los meta-análisis que confirman el buen rendimiento de esta prueba diagnóstica (3).

Sin embargo, a pesar de toda esta evidencia favorable, el último reporte global de tuberculosis de la OMS (4) indica que muy pocos países han implementado MODS a pesar de haber sido avalado por la OMS en el 2009. Lo mismo ocurre con otros métodos avalados por la OMS, así solo el $67 \%$ de países han implementado cultivo líquido avalado en 2007, 44\% usan pruebas moleculares LPA (line probe assays) avalado el 2008, y 33\% usan Xpert MTB/RIF avalado en 2010. Por lo que podemos decir que la lenta respuesta para implementar estos nuevos métodos rápidos no es solo un problema de Perú. 
El grupo de desarrollo del MODS ha hecho múltiples esfuerzos para facilitar la implementación de la prueba haciéndola de reproducción libre, publicando los manuales de elaboración (5) y brindando asesoría o control de calidad en línea vía internet (http://modsperu.org/). Se debe resaltar que para la implementación de métodos diagnósticos no solo es necesario el entrenamiento del personal para la transferencia tecnológica, sino que se deben adecuar los laboratorios para asegurar el equipamiento necesario para la prueba y además las medidas de bioseguridad necesarias.

Para simplificar el equipamiento necesario para la implementación del MODS, investigadores de la Universidad Nacional de Ingeniería y la Universidad Peruana Cayetano Heredia han desarrollado con éxito alternativas económicas para reemplazar el microscopio invertido incluso hasta con cámaras digitales convencionales (6). Este desarrollo no solo reduce los costos de equipamiento, sino que permite el desarrollo de lectores automatizados de placas MODS (7), reduciendo la necesidad de entrenamiento y tiempo para lectura de placas del personal a cargo de esta prueba.

Para fortalecer la capacidad de detectar resistencia y establecer diagnóstico rápido de $\mathrm{TB}$, el proyecto EXPAND-TB (iniciativa global de múltiples socios incluido OMS, FIND, UNITAID, etc.) implementa métodos rápidos en 27 países, con buenos resultados (4). Los métodos implementados incluyen cultivos líquidos y pruebas moleculares (LPA), pero no ha incluido el MODS en el Perú.

Los reportes de implementación en el Perú han mostrado significativas ventajas usar el MODS (8) sobre el GRIESS (9) teniendo mejor performance en contaminación $2,3 \%$ vs $7,3 \%$ y tiempo a detección de MTB 12,9 vs 31 días; por lo que sorprende que la decisión de propiciar la implementación de MODS sobre GRIESS haya demorado tanto. Felizmente para este año la ESNPCT ha anunciado aumento de implementación MODS en varias otras regiones del país. A pesar de estas buenas noticias, en necesario que el sistema nacional de laboratorios se pueda mejorar para asegurar la bioseguridad del manejo de cultivos líquidos incluyendo el envío de cepas para referencia y control de calidad. Compartimos la necesidad de acelerar la implementación de pruebas rápidas como el MODS en diferentes ciudades del país, pero esta se debe hacer asegurando las medidas de control de calidad y bioseguridad en los laboratorios regionales.
Carlos Zamudio

Médico - Cirujano

Instituto Medicina Tropical Alexander von Humboldt. Universidad Peruana Cayetano Heredia

\section{REFERENCIAS BIBLIOGRÁFICAS}

1. Caviedes L, Lee T-S, Gilman RH, Sheen P, Spellman E, Lee EH, et al. Rapid, Efficient Detection and Drug Susceptibility Testing of Mycobacterium tuberculosis in Sputum by Microscopic Observation of Broth Cultures. J Clin Microbiol. 2000; 38(3):1203-8.

2. Ha DTM, Lan NTN, Kiet VS, Wolbers M, Hang HTT, Day J, et al. Diagnosis of Pulmonary Tuberculosis in HIV-Positive Patients by Microscopic Observation Drug Susceptibility Assay. J Clin Microbiol. 2010; 48(12):4573-9.

3. Minion J, Leung E, Menzies D, Pai M. Microscopicobservation drug susceptibility and thin layer agar assays for the detection of drug resistant tuberculosis: a systematic review and meta-analysis. Lancet Infect Dis. 2010; 10(10):688-98.

4. World Health Organization. Global tuberculosis report 2012. Geneva: World Health Organization; 2012.

5. Brady MF, Coronel J, Gilman RH, Moore DA. The MODS method for diagnosis of tuberculosis and multidrug resistant tuberculosis. J Vis Exp. [Internet]. 2008 Aug 11 [cited 2013 Apr 27]; (17). Available from: http://www.jove.com/index/Details.stp?ID= 845

6. Zimic M, Velazco A, Comina G, Coronel J, Fuentes $\mathrm{P}$, Luna CG, et al. Development of low-cost inverted microscope to detect early growth of Mycobacterium tuberculosis in MODS culture. Plos One. 2010; 5(3):e9577.

7. Comina G, Mendoza D, Velazco A, Coronel J, Sheen P, Gilman RH, et al. Development of an automated MODS plate reader to detect early growth of Mycobacterium tuberculosis. J Microsc. 2011; 242(3):325-30.

8. Mendoza A, Castillo E, Gamarra N, Huamán T, Perea M, Monroi Y, et al. Reliability of the MODS assay decentralisation process in three health regions in Peru. Int J Tuberc Lung Dis. 2011; 15(2):217-22.

9. Asencios L, Yale G, Yagui M, Quispe N, Taylor A, Blaya J, et al. Programmatic implementation of rapid DST for Mycobacterium tuberculosis in Peru. Int J Tuberc Lung Dis. 2008; 12(7):743-9. 